\title{
ATP-Binding and -Hydrolysis Activities of ALDP (ABCD1) and ALDRP (ABCD2), Human Peroxisomal ABC Proteins, Overexpressed in Sf21 Cells
}

\author{
Masashi Morita, ${ }^{*, a}$ Mikinori Kurisu, ${ }^{a}$ Yoshinori KashiwaYama, ${ }^{a}$ Sadaki Yokota, ${ }^{b}$ and \\ Tsuneo IMANAKA ${ }^{a}$ \\ ${ }^{a}$ Department of Biological Chemistry, Graduate School of Medicine \& Pharmaceutical Sciences, University of Toyama; \\ 2630 Sugitani, Toyama 930-0194, Japan: and ${ }^{b}$ Biological Laboratory, Yamanashi University School of Medicine; 1100 \\ Shimokatou, Tamaho 409-3898, Japan. Received May 13, 2006; accepted June 6, 2006; published online June 14,2006
}

\begin{abstract}
The peroxisomal ATP-binding cassette (ABC) proteins, adrenoleukodystrophy protein (ALDP, ABCD1) and ALD-related protein (ALDRP, ABCD2), were expressed in Spodoptera frugiperda 21 (Sf21) insect cells using a baculovirus-mediated expression system. Immunoelectron microscopy and subcellular fractionation revealed that the overexpressed ALDP was distributed in various subcellular organelles including mitochondria, nucleus and peroxisomes. The ALDP was not extractable with $\mathrm{Na}_{2} \mathrm{CO}_{3}$ treatment, suggesting that it integrated into membranes. ATPase activity was detected in the membrane fraction expressing ALDP. The nucleotide-binding capacities of the expressed ALDP were estimated by the binding to ATP- or ADP-agarose. ALDP exhibited an affinity to both ADP and ATP. In contrast, ALDRP exhibited an affinity to ADP but scarcely to ATP. The ALDP in the Sf21 membrane fraction was extracted with $n$-dodecyl- $\beta$-maltoside and successively purified with a chelate column. The nucleotide-binding and ATPase activities of the purified ALDP were, however, not detected. It may be that certain membranous components are required for the activity. We demonstrate for the first time that the peroxisomal ABC proteins can be expressed in Sf21 membranes maintaining their nucleotide-binding abilities and ATPase activities, and the expressed proteins will be of use for further characterization.
\end{abstract}

Key words adrenoleukodystrophy protein; peroxisome; Spodoptera frugiperda 21 insect cell; ATP-binding cassette (ABC) protein

ATP-binding cassette $(\mathrm{ABC})$ proteins play an important role in the transport of various substrates across cell membranes powered by ATP molecules. ${ }^{1)}$ ABC proteins contain two sets of multi-spanning transmembrane domain(s) (TMD) and highly conserved nucleotide-binding domain(s) (NBD) which are composed of Walker A, Walker B and ABC signature motifs. They are ubiquitous in prokaryotes and eukaryotes, and represent one of the largest families of proteins. So far, more than 50 human $\mathrm{ABC}$ proteins have been identified and nearly half are thought to be involved in lipid transport.

Peroxisomes are bounded by a single membrane and fulfill important roles in lipid metabolism, including the $\beta$-oxidation of very long- and branched-chain fatty acids, and the biosynthesis of plasmalogen and bile acids. ${ }^{2,3)}$ Transport of substrates for $\beta$-oxidation across the peroxisomal membrane is an essential step in this metabolism. Peroxisomal ABC proteins have been implicated in this transport.

$\mathrm{X}$-Linked adrenoleukodystorophy (X-ALD) is the most common peroxisomal disorder, affecting approximately 1 in 15000 - 30000 males in Japan. ${ }^{4,5)}$ This hereditary disease is characterized by progressive neuron demyelination, adrenal insufficiency and testicular dysfunction. The biochemical characterization of the disease is based on the accumulation of pathognomonic amounts of saturated very long chain fatty acids (VLCFA, $>$ C22) in all tissues, including brain white matter and adrenal glands, and also in skin fibroblasts. ${ }^{6,7)}$ The accumulation of very long chain fatty acids in X-ALD is linked to mutations in the $A L D(A B C D 1)$ gene, with an $\mathrm{ABC}$ subfamily D. The $A L D$ gene product, called "ALDP", is thought to be involved in the transport of VLCFA or VLCFA-CoA into the peroxisomes by analogy to its yeast homolog Pxa1p and Pxa2p. In fact, yeast lacking one or both of the two ABC proteins (Pxalp and Pxa2p) accumulate VLCFA and do not grow in oleic acid as the sole carbon source ${ }^{8,9)}$ It is thus thought that the dysfunction of ALDP leads to a decrease of VLCFA $\beta$-oxidation in the peroxisome, which results in the accumulation of VLCFA. However, the precise function of ALDP and the association between the reduction of VLCFA $\beta$-oxidation and the accumulation of VLCFA are still undetermined.

To date, three additional $\mathrm{ABC}$ proteins have been identified as homologs of ALDP, ALDRP (ABCD2), ${ }^{10)}$ a 70 -Da peroxisomal membrane protein (PMP70, ABCD3) ${ }^{11)}$ and PMP70-related protein (P70R, ABCD4). ${ }^{12)}$ They display $63 \%$ (ALDRP), 36\% (PMP70) and 25\% (P70R) amino acid identity with ALDP. PMP70 is a major peroxisomal membrane protein but P70R has not been detected in peroxisomes. The amount of ALDP and ALDRP is less than 1/7 that of PMP70 in rat liver peroxisomes. ${ }^{13,14)}$ Since these peroxisomal ABC proteins consist of one TMD and one NBD, they must dimerize to become a functional unit.

We previously reported that PMP70 is active in the metabolic transport of long chain acyl-CoA into the peroxisomal matrix. ${ }^{15)}$ Recently, we have demonstrated that rat liver PMP70 and ALDP bind to ATP and hydrolyze ATP by photoaffinity labeling of 8 -azide- $\left[\gamma^{32} \mathrm{P}\right] \mathrm{ATP}$ and 8 -azide- $[\alpha$ $\left.{ }^{32} \mathrm{P}\right] \mathrm{ATP}$ and that the binding and hydrolysis of ATP comes about via conformational changes. ${ }^{13)}$ These results indicate that ATP-binding and -hydrolysis is required for functional transport. However, a precise characterization of PMP70, ALDP and especially ALDRP has not yet been carried out. In our early study, we could not detect ATPase activities of peroxisomal $\mathrm{ABC}$ proteins due to the existence of another kind of ATPase(s) even in purified rat liver peroxisomal fraction. ${ }^{16)} \mathrm{Up}$ to date, there is no report that ATPase activities of peroxisomal $\mathrm{ABC}$ proteins has been measured as native proteins. A major obstacle to fully understanding the structure and function of ALDP and ALDRP has been the difficulty in 
purifying sufficient biochemical quantities of the active proteins because the expression of these $\mathrm{ABC}$ proteins is very low in human tissues and cell lines. Attempts to express and characterize human ALDP by a bacterial expression system have also failed. Baculovirus-mediated expression systems have been used to express large quantities of a variety of functional eukaryotic recombinant $\mathrm{ABC}$ proteins, including MDR $1,{ }^{17)}$ breast cancer resistant protein (BCRP, ABCG2) ${ }^{18)}$ and the transporters of antigenic peptides (TAP1 and TAP2). ${ }^{19)}$ We thus decided to express human ALDP and ALDRP in insect cells using a baculovirus-mediated expression system to obtain the large quantities required for further investigating their function. We demonstrate that ALDP and ALDRP overexpression in Sf21 cells retains the nucleotidebinding and ATPase activities, and that the nucleotide-binding capacity of ALDP was different from that of ALDRP. This is the first report of ATPase activities of ALDP and ALDRP as full-length proteins.

\section{MATERIALS AND METHODS}

Baculovirus and Insect Cells The insect cell line (Sf21), the baculovirus transfer vectors (pBlueBac4.5 and pBlueBacHis2), baculovirus (Bac-N-Blue DNA) and Grace's insect cell medium were purchased from Invitrogen (Carlsbad, CA, U.S.A.). Sf21 insect cells were cultured in Grace's insect medium containing $10 \%$ fetal bovine albumin and gentamycin (final $10 \mu \mathrm{g} / \mathrm{ml}$ ) at $26^{\circ} \mathrm{C}$.

Preparation of Recombinant Baculoviruses Recombinant baculovirus were prepared using a Bac-N-Blue Transfection Kit and baculovirus transfer vectors (pBlueBac4.5 and pBlueBacHis2) according to the manufacturer's instructions and infected into Sf21 cells.

Baculovirus transfer vectors harboring $A L D H i$ is or $A L D R$ cDNA were generated as follows. For construction of $A L D$ with the histidine-tag sequence, PCR was performed with pMAM2-BSD/ALD as the template using two sets of oligonucleotide primers designed on the basis of their sequences: a forward primer (5'-CCTGTGGTATGTTATGCTGGAG- $3^{\prime}$ ) and a reverse primer having an $X b a$ I site and the His-tag sequence (5'-GGACGTCTAGATCAATGATGATGATGATGATGGGTGGAGGCACCCTGGA-3' ${ }^{\prime}$ ). The amplification products were digested with NotI and $X b a \mathrm{I}$ sites and cloned into the same restriction sites of a pcDNA3.1 vector ( $p c D N A 3.1+/ A L D H i s) . p c D N A 3.1+$ IALDHis was then digested with XhoI and NheI, and the fragment was subcloned into the same restriction sites of pBlueBac4.5 (pBlueBac4.5/ALDHis).

For construction of $\mathrm{pBlueBacHis/ALDR}$, we first cloned $A L D R$ cDNA using a PCR-based protocol. PCR was performed with the human brain cDNA library (TaKaRa, Japan) as the template using two sets of oligonucleotide primers designed on the basis of GeneBank (accession No. AJ000327). The $A L D R$ cDNA was then subcloned into pBlueBacHis2 ( $p$ BlueBacHis/ALDR). The cDNA sequences were confirmed by dye-terminator cycle sequencing using an ABI PRISM 310 (PE Applied Biosystems).

The purified recombinant transfer vector ( $p$ BlueBac/ALDHis or $p$ BlueBacHis/ALDR), together with linearized baculoviral DNA, was co-transfected into Sf21 cells using Transfection Reagent purchased from BD Biosciences
Pharmingen (San Jose, CA, U.S.A.) and used according to the manufacturer's instructions. At $2 \mathrm{~d}$ postinfection, the supernatant of the culture was serially diluted and used for next infection. Negative recombinant plaques were recognized by blue-white selection and confirmed by PCR amplification. Individual clones expressing high levels of human ALDP and ALDRP were obtained by end-point dilution and subsequent amplification. The clone producing the highest yield of these proteins was selected by immunoblot analysis. The purified recombinant viral stocks were stored at $4{ }^{\circ} \mathrm{C}$ and used for infection. The infection was routinely performed with a multiplicity of infection (m.o.i.) of about $3-5$. The recombinant baculovirus carrying the $\beta$-galactosidase gene was used as control.

Membrane Preparation All procedures were carried out at $4{ }^{\circ} \mathrm{C}$. After $36 \mathrm{~h}$ postinfection, the Sf21 cells were harvested and suspended in Tris-mannitol buffer $(50 \mathrm{~mm}$ Tris, $\mathrm{pH} 7.0$, containing $300 \mathrm{~mm}$ mannitol, $0.5 \mathrm{~mm}$ PMSF and $10 \mu \mathrm{g} / \mathrm{ml}$ of leupeptin, antipain, chymostatin, and pepstatin A). For membrane preparation, the cells were homogenized using a glass-Teflon tissue homogenizer (40 strokes) in TMEP buffer (50 mM Tris, pH 7.0, containing $50 \mathrm{~mm}$ mannitol, $2 \mathrm{~mm}$ EGTA, $0.5 \mathrm{~mm}$ PMSF and $10 \mu \mathrm{g} / \mathrm{ml}$ of leupeptin, antipain, chymostatin, and pepstatin A), and the nucleus and other debris were removed by centrifugation at $700 \times \boldsymbol{g}$ for $10 \mathrm{~min}$. After a centrifugation at $100000 \times \mathbf{g}$ for $1 \mathrm{~h}$, the pellet (as the membrane fraction) was resuspended in TMEP buffer and stored in aliquots at $-80^{\circ} \mathrm{C}$ until use.

Subcellular Fractionation of Sf21 Cells Fractionation was carried out as described previously. ${ }^{20)}$ Approximately $90 \%$ confluent cells in $75-\mathrm{cm}^{2}$ culture flasks were washed 3 times with phosphate-buffered saline (PBS). All procedures were carried out at $4{ }^{\circ} \mathrm{C}$. The cells were harvested and homogenized with a Teflon/glass Potter-Elvehjem homogenizer in 10 volumes $(3 \mathrm{ml})$ of homogenization buffer $(0.25 \mathrm{M} \mathrm{su}$ crose, $1 \mathrm{~mm}$ EDTA, 0.1\% (w/v) ethanol, $3 \mathrm{~mm}$ imidazole, $\mathrm{pH}$ 7.0). The homogenate was first fractionated by different centrifugations to prepare the mitochondrial and light mitochondrial (ML) fractions according to the method of de Duve et $a l{ }^{21)}$ The ML fractions were then subjected to an equilibrium density centrifugation in a $10.6 \mathrm{ml}$ linear sucrose gradient $(1.10-1.20 \mathrm{~g} / \mathrm{ml})$ in a Beckman NVT65 rotor. The gradient rested on $0.5 \mathrm{ml}$ of $1.27 \mathrm{~g} / \mathrm{ml}$ sucrose. The centrifugation was carried out at $193000 \times \boldsymbol{g}$ for $90 \mathrm{~min}$ at $4{ }^{\circ} \mathrm{C}$. About $1 \mathrm{ml}$ of the fraction was collected in pre-weighted microtubes from the bottom, and the density of each fraction was determined by refractometry.

Immunofluorescence and Immunoelectron Microscopy Immunofluorescence was performed as described previously. ${ }^{22)}$ For immunoelectron microscopy, Sf21 cells were fixed with $0.1 \mathrm{M}$ Hepes buffer $(\mathrm{pH} 7.4)$ containing $4 \%(\mathrm{w} / \mathrm{v})$ paraformaldehyde and $0.2 \%(\mathrm{w} / \mathrm{v})$ glutaraldehyde for $1 \mathrm{~h}$ at room temperature. After being washed with PBS, the cells were dehydrated with graded ethanol at $-20^{\circ} \mathrm{C}$ and embedded in LR White. Polymerization of the resin was performed under UV light at $-20^{\circ} \mathrm{C}$ for $24 \mathrm{~h}$. Thin sections were cut with a diamond knife equipped with an Ultracut $\mathrm{R}$ microtome (Reichert, Germany) and mounted on nickel grids. Sections were incubated with primary anti ALDPHis antibody overnight at $4{ }^{\circ} \mathrm{C}$, followed by 30 min-incubation with a protein A-gold probe (15 $\mathrm{nm}$ in diameter). Sections were then 
doubly contrasted with uranyl acetate and lead citrate and examined with a Hitachi H7000 transmission electron microscope (Hitachi, Tokyo, Japan) at an acceleration voltage of $80 \mathrm{kV}$.

Purification of ALDPHis Purification of ALDPHis was performed by immobilized metal affinity chromatography. All procedures were carried out at $4{ }^{\circ} \mathrm{C}$. Crude membrane fractions were solubilized in $50 \mathrm{~mm}$ Tris- $\mathrm{HCl}(\mathrm{pH} 7.0)$ containing $500 \mathrm{~mm} \mathrm{NaCl}, 5 \mathrm{~mm}$ imidazole, $20 \%(\mathrm{v} / \mathrm{v})$ glycerol and $1 \% n$-dodecyl- $\beta$-maltoside for $24 \mathrm{~h}$ with rotation. After a centrifugation at $14000 \times \boldsymbol{g}$ for $20 \mathrm{~min}$, the solubilized proteins were diluted with the same buffer to adjust the final concentration of $n$-dodecyl- $\beta$-maltoside to $0.1 \%$. The sample was then applied onto a column (bed volume $1 \mathrm{ml}$ ) of TALON metal affinity resin (Clontech) pre-equilibrated with the buffer containing $0.1 \% n$-dodecyl- $\beta$-maltoside. Unbound materials were washed with the same buffer followed by the same buffer containing $25 \mathrm{~mm}$ imidazole. Absorbed proteins were then eluted with the buffer containing $200 \mathrm{~mm}$ imidazole. Fractions of $0.5 \mathrm{ml}$ were collected and concentrated by ultrafiltration with an amicon concentrator (Amicon). Aliquots of the sample were analyzed by immunoblotting.

ATPase Activity The ATPase activity of the membrane fraction was estimated by measuring inorganic phosphate liberation according to the method of Chifflet et $a l^{23)}$ The membrane fractions (about $10 \mu \mathrm{g}$ of membrane protein) were incubated at $37^{\circ} \mathrm{C}$ in $0.1 \mathrm{ml}$ of $40 \mathrm{~mm}$ Tris- $\mathrm{HCl}$ (pH 7.4) containing $0.1 \mathrm{~mm}$ EGTA, $1 \mathrm{~mm}$ dithiothreitol, $2 \mathrm{~mm}$ ouabain and $15 \mathrm{mM} \mathrm{MgSO}_{4}$, and the ATPase reaction was started by the addition of $5 \mathrm{~mm}$ NaATP. The reaction was stopped by the addition of $0.1 \mathrm{ml}$ of $12 \%(\mathrm{w} / \mathrm{v})$ sodium dodecyl sulfate (SDS). For the reduction of the complex, $0.2 \mathrm{ml}$ of $1 \%(\mathrm{w} / \mathrm{v})$ ascorbic acid was added and the optical density read at $850 \mathrm{~nm}$.

ATP- or ADP-Agarose Binding Assay Nucleotidebinding activities were estimated by the ability to bind to ATP- and ADP-agarose. The rat liver peroxisome fraction and the crude membrane fraction from Sf21 cells expressing ALDPHis were suspended in a solubilization buffer $(50 \mathrm{~mm}$ Tris- $\mathrm{HCl}$ ( $\mathrm{pH} 7.0$ ) containing $150 \mathrm{~mm} \mathrm{NaCl}, 5 \mathrm{~mm} \mathrm{MgCl}_{2}$ and $20 \%$ glycerol) containing $0.5 \% n$-dodecyl- $\beta$-maltoside and incubated for $30 \mathrm{~min}$ at $4{ }^{\circ} \mathrm{C}$. Glycerol was added to the membrane fraction to stabilize the protein. Agarose beads were added to the mixture to remove nonspecific materials bound to agarose. After centrifugation at $14000 \times \boldsymbol{g}$ for $15 \mathrm{~min}$, the supernatants were rotated for $24 \mathrm{~h}$ at $4{ }^{\circ} \mathrm{C}$ in the presence or absence of $10 \mathrm{~mm}$ ATP or ADP. ATP- or ADPagarose (N-6 attachment; Sigma) were then added to the reaction and the mixture was rotated for a further $24 \mathrm{~h}$. After centrifugation for $30 \mathrm{~min}$ at $14000 \times \boldsymbol{g}$, the pellet was washed three times with the solubilization buffer containing $0.05 \%$ $n$-dodecyl- $\beta$-maltoside. The proteins absorbed with ATP- or ADP-agarose were dissolved in SDS sample buffer containing $10 \mathrm{~mm}$ EDTA and subjected to SDS-PAGE followed by immunoblotting.

Other Methods Measurement of the enzyme activities such as catalase, $N$-acetyl- $\beta$-glucosaminidase, cytochrome $c$ oxidase and NADPH cytochrome $c$ reductase in Sf21 cells was performed as described previously. ${ }^{20)}$ Preparation of rat liver peroxisomes ${ }^{13)}$ and immunoblotting ${ }^{22)}$ using rabbit antiALDP and ALDRP antibodies ${ }^{24)}$ were performed as described previously. The protein concentration was determined by the method of Bradford using immunoglobulin as the standard. ${ }^{25)}$

\section{RESULTS}

Expression of ALDPHis in Sf21 Cells ALDP was expressed in Sf21 cells using a baculovirus-mediated expression system. To facilitate the purification process, we expressed ALDP as fusion proteins with a histidine-tag at the C-terminal (ALDPHis). The time-dependent expression of ALDPHis was analyzed by immunoblotting (Fig. 1). The ALDPHis became immunodetectable within $1 \mathrm{~d}$ and protein expression was observed to increase gradually up to $4 \mathrm{~d}$ after the infection. At $4 \mathrm{~d}$ postinfection, however, some extra bands greater than $170 \mathrm{kDa}$, suggesting that the overexpressed proteins could be nonspecifically aggregated in the cells. We therefore used $36 \mathrm{~h}$ postinfection cells in further experiments.

Subcellular Distribution of the ALDPHis We first analyzed the distribution of ALDPHis in the baculovirus-infected cells at $36 \mathrm{~h}$ postinfection by immunofluorescence studies. The fluorescent dots of ALDPHis appeared to be distributed in cytoplasmic organelles except for the nucleus (Fig. 2A). Therefore, we analyzed the distribution in subcellular fractions. Upon subcellular fractionation (Fig. 2B, upper), mitochondria (Cyt $\mathrm{Ox}$, cytochrome $c$ oxidase), lysosomes (NAGase, $N$-acetyl- $\beta$-glucosaminidase) and endoplasmic reticulum (Cyto Red, cytochrome $c$ reductase) were well separated by a sucrose density gradient centrifugation. In Sf21 cells, catalase activity, which is known as a predominant peroxisomal marker enzyme, was undetected. We have previously demonstrated that $\mathrm{Sf} 21$ cells have peroxisomes lacking detectable catalase activity. ${ }^{22)}$ In this experimental condition, the peroxisomes were fractionated at a greater density than mitochondria (fraction No. 8 or 9) as described previously. However, ALDPHis appeared to be distributed not only in peroxisomes but also in various subcellular fractions, including mitochondria, lysosomes and ER (Fig. 2B,

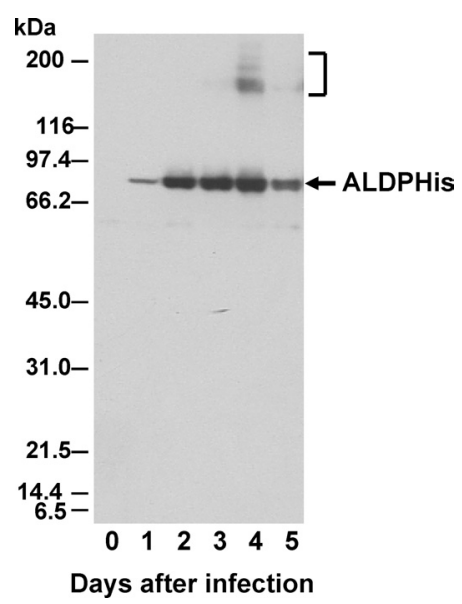

Fig. 1. Expression of ALDPHis in Sf21 Insect Cells

Sf21 cells were infected with a recombinant baculovirus harboring ALDHis (m.o.i. $=3-5$ ). At different times postinfection, cells were harvested and subjected to immunoblotting. The cell homogenates $(20 \mu \mathrm{g} /$ lane $)$ were separated by $7-15 \%$ SDSPAGE and transferred to PVDF membranes. Immunoblot analyses of the transferred proteins were performed using antibody against human ALDP. ALDPHis was detected at molecular weights of approximately $80 \mathrm{kDa}$. Cell lysates infected with Bac-NBlue/ $\beta$-gal as a mock control did not express immunodetectable proteins (data not shown). 
A
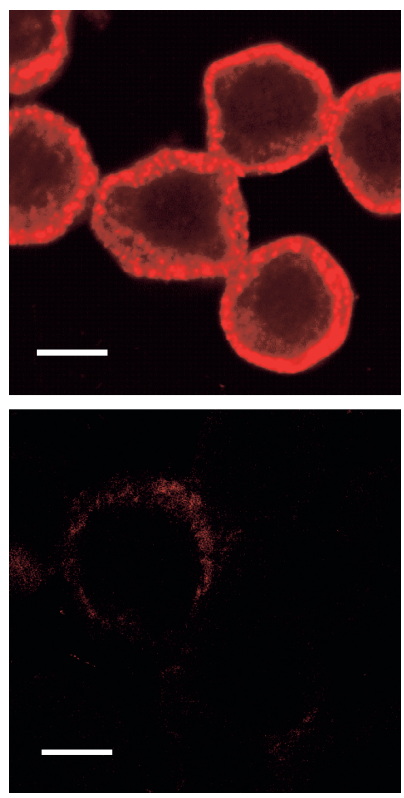

B

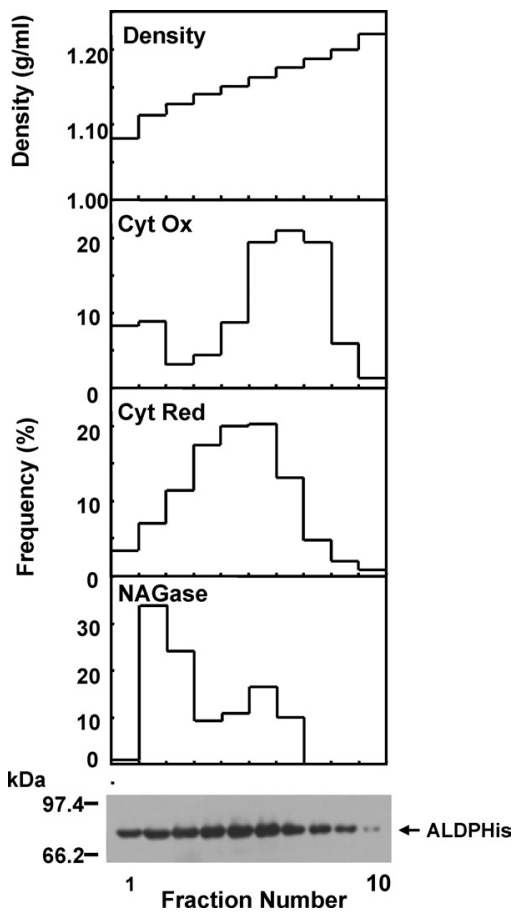

C

$36 \mathrm{~h}$
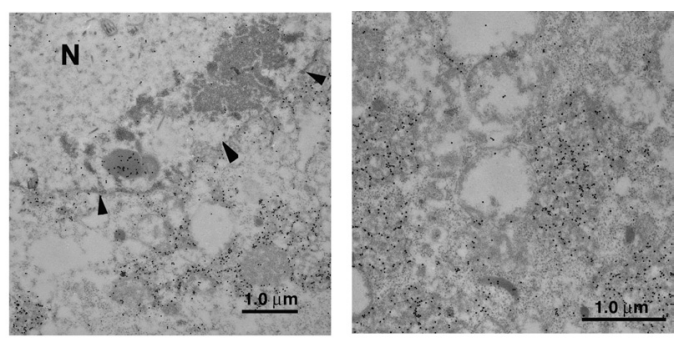

$72 \mathrm{~h}$

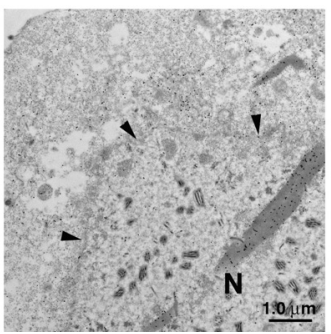

D $\mathrm{Na}_{2} \mathrm{CO}_{3}$ treatment

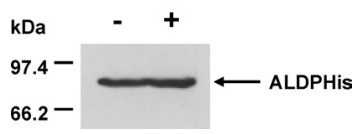

Fig. 2. Distribution of ALDPHis in Sf21 Insect Cells

Distribution of ALDPHis expressed in Sf21 cells was analyzed by immunofluorescence (A), subcellular fractionation followed by immunoblotting (B), immunoelectronmicroscopy (C) and alkaline treatment (D). A, Sf21 cells infected with baculoviruses harboring ALDHis (upper) or $\beta$-galactosidase (lower) were analyzed by immunofluorescence. At $4 \mathrm{~d}$ postinfection, cells were fixed, permeabilized and reacted with anti-ALDP antibody followed by anti-rabbit Cy 3 coupled antibody. Fluorescence was analyzed with confocal laser scanning microscopy (Carl Zeiss LSM510, Jena, Germany). The negative control expressing $\beta$-galactosidase shows some faint background signals. Bar=5 $\mu$ m. B, Sf 11 cells were fractionated by a differential centrifugation followed by an isopycnic centrifugation in a sucrose gradient. Cytochrome $c$ oxidase (Cyt Ox), NADPH cytochrome $c$ reductase (Cyt Red) and $N$-acetyl- $\beta$-D-glucosaminidase (NAGase) were measured as marker enzymes of mitochondria, microsomes and lysosomes, respectively. Catalase activity was not detected in Sf21 cells. An aliquot (30 $\mu$ l) of each fraction from the top (No. 1) to the bottom (No. 11) in the sucrose gradient was subjected to electrophoresis in a 7-15\% acrylamide gradient gel. The proteins were transferred onto PVDF membrane and immunoreacted with anti-ALDP antibody. C, immunogold electron microscopic localization of ALDPHis in $\mathrm{Sf} 21$ cells at $36 \mathrm{~h}$ or $72 \mathrm{~h}$ postinfection. The arrowheads indicate the nuclear membrane. N: nucleus. Gold particles exhibiting ALDPHis were detected in various membranous structures in cytoplasm, some distributed in membranes and others aggregated in the nucleus. D, The crude membrane fractions containing ALDPHis were treated with $0.1 \mathrm{M}$ sodium carbonate. After centrifugation, the insoluble materials were separated by $7-15 \%$ SDS-PAGE and subjected to immunoblot analyses using anti-ALDP antibody.

bottom). This result was supported by immunoelectron microscopy (Fig. 2C). The gold particle dots corresponding to ALDPHis were detected in various membranous structures at $36 \mathrm{~h}$ postinfection. At $72 \mathrm{~h}$ postinfection, crystalloid-like structures were observed in the nucleus, suggesting that ALDPHis had become aggregated there as well.

Most ALDPHis was recovered in the crude membrane fraction and was not extractable with $0.1 \mathrm{M}$ sodium carbonate (Fig. 2D), indicating that the ALDPHis existed in the form of integral membrane proteins.

ATPase and Nucleotide-Binding Activities of ALDPHis The ATPase activities in the crude membrane fractions expressing the heterologous proteins were examined. The activity of the membrane expressing ALDPHis $(77 \pm 4 \mathrm{nmol} /$ $\mathrm{mg} / \mathrm{min}$ ) was significantly higher than that expressing $\beta$ galactosidase $(50 \pm 4 \mathrm{nmol} / \mathrm{mg} / \mathrm{min})$, suggesting that expressed ALDPHis has significant ATP-hydrolyzing activity. In this condition, ATP was hydrolyzed in a time-dependent manner and the released phosphate ions increased linearly for $30 \mathrm{~min}$. The ATPase activity was insensitive to oligomycin, azide and vanadate. This is consistent with our previous finding that ALDP in rat peroxisomes did not form a stable inhibitory complex after hydrolysis in the presence of orhtovanadate. ${ }^{13)}$

Using ATP- or ADP-agarose, we elucidated the nucleotide-binding activities of the ALDPHis in Sf21 mem- branes as well as ALDP in rat liver peroxisomes. As shown in Fig. 3 (upper), ALDP in rat liver peroxisomes was absorbed to both ATP- and ADP-agarose and the absorption was significantly decreased in the presence of ATP or ADP, respectively, indicating that the ALDP has the capacity to bind both ATP and ADP. This result is consistent with our previous results using 8-azide ATP and ADP. ${ }^{13)}$ ALDPHis in Sf21 membranes also has the capacity to bind both ATP and ADP, as does ALDP in rat liver peroxisomes (Fig. 3, middle). Similar results were observed in the expressed ALDP with fusion of a histidine-tag at $\mathrm{N}$ and $\mathrm{C}$-terminal (data not shown). These results suggest the ALDP expressed in the Sf21 membranes retains both its nucleotide-binding and ATP-hydrolyzing activities.

We also expressed ALDRP as fusion proteins with a histidine-tag at the N-terminal. The membrane fraction expressing ALDRP exhibited significant ATPase activities $(74 \pm 3$ $\mathrm{nmol} / \mathrm{mg} / \mathrm{min})$. Interestingly, ALDRP appeared to have a higher binding capacity for ADP but only scarce capacity for ATP (Fig. 3, bottom). The role of ALDRP in the ATP hydrolyzing reaction might be different from that of ALDP. In this experiment, we were not able to analyze the ALDRP in rat liver peroxisomes because of the low level of expression.

Solubilization and Purification of ALDPHis from Membrane Fractions Next, we purified ALDPHis using a metal-chelate resin in terms of the histidine-tag. The protein 

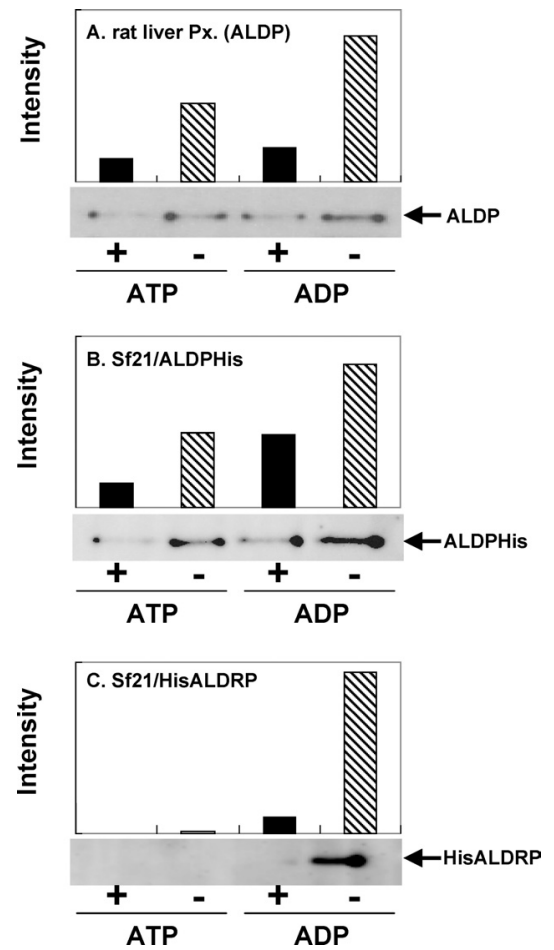

Fig. 3. Nucleotide-Binding of ALDP and ALDRP in Sf21 Cell Membranes

Sf21 membrane fractions expressing ALDPHis (B) or HisALDRP (C) as well as rat liver peroxisomes (A) were dissolved in a buffer containing $0.5 \% n$-dodecyl- $\beta$-maltoside for $24 \mathrm{~h}$ at $4{ }^{\circ} \mathrm{C}$. The extracts were then incubated with ATP- or ADP-agarose for $24 \mathrm{~h}$ in the absence $(-)$ or presence $(+)$ of ATP or ADP, respectively. The proteins bound to ATP-agarose or ADP-agarose were subjected to SDS-PAGE, transferred onto PVDF membranes, and probed with anti-ALDP (A and B) and anti-ALDRP antibodies (C). Relative intensity of ALDP or ALDRP on the PVDF membrane was analyzed by scanning with a luminoimaging analyzer (LAS-1000 plus; Fuji Photo Film Co., Tokyo, Japan). Experiments were carried out at least three times, and the same results were obtained.

was solubilized with a buffer containing $0.5 \% n$-dodecyl- $\beta$ maltoside. Using this detergent, more than $50 \%$ of the proteins were solubilized from the membrane fraction. Triton $\mathrm{X}$ $100(1.0 \%, \mathrm{w} / \mathrm{v})$, digitonin $(1.5 \%, \mathrm{w} / \mathrm{v})$ and zwittergent $3-$ $10(1.5 \%, \mathrm{w} / \mathrm{v})$ were also effective. The ALDPHis was purified by a metal-chelate column (Fig. 4A) and the purified ALDPHis appeared as a single band on SDS-PAGE followed by CBB stain (Fig. 4B), suggesting that the protein was substantially purified. We have attempted to detect the ATPase and ATP-binding activities of the purified ALDPHis after reconstitution in liposomes with asolectin or phosphatidylethanolamine, but have not been successful thus far. It may be that certain membranous components are required for the activities.

\section{DISCUSSION}

Among the peroxisomal $\mathrm{ABC}$ proteins, PMP70 is the major constituent of the peroxisomal membrane protein. In comparison to PMP70, the amount of ALDP and ALDRP is very low. ${ }^{13)}$ It has not yet been characterized the ATPase activities of full-length peroxisomal $\mathrm{ABC}$ proteins, even PMP70. We tried to express ALDP in CHO cells or E. coli, but the expression level was too low to analyze the biological activities. In the present study, abundant expression of ALDP has been achieved with a baculovirus-mediated expression
A

B
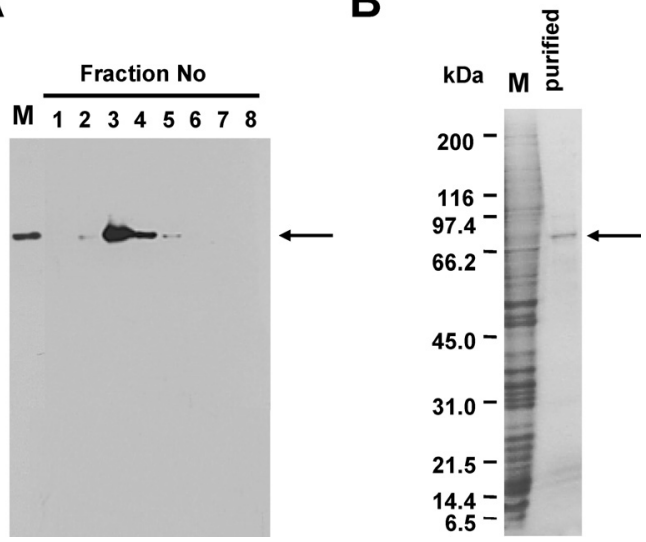

Fig. 4. Purification of ALDPHis with a TALON Metal Affinity Resin

(A) The membrane fractions from Sf21 cells $36 \mathrm{~h}$ postinfection were lysed with a buffer containing $1 \% n$-dodecyl- $\beta$-maltoside overnight at $4{ }^{\circ} \mathrm{C}$. After a centrifugation, the supernatants were applied onto a column (bed volume $1 \mathrm{ml}$ ) of TALON metal affinity resin. Unbound materials were washed out with the same buffer containing $50 \mathrm{~mm}$ imidazole and purified ALDPHis were eluted from the column with $200 \mathrm{~mm}$ imidazole. Fractions of $0.5 \mathrm{ml}$ were collected. The aliquots of each fraction were subjected to SDS-PAGE followed by immunoblotting. The purified ALDPHis in fractions No. 3 and 4 were collected and concentrated by ultrafiltration with an amicon concentrator (Amicon). M; crude membrane fraction (10 $\mu \mathrm{g}$ protein). (B) The purified ALDPHis (40 $\mu \mathrm{g}$ protein) and the crude membrane fraction (M) (40 $\mu \mathrm{g}$ protein) were electrophoresed and the gel was stained with CBB. The arrow indicates the position of ALDPHis.

system. The ALDP was located in organelle membranes of the Sf21 cells at $36 \mathrm{~h}$ (Fig. 2A) and its nucleotide binding properties was similar to those of ALDP in rat liver peroxisomes (Fig. 3), suggesting that ALDP expressed in the Sf21 cells exists as native form. The unspecified distribution of the heterologous ALDP in various cellular membranes is a result of the low number of peroxisomes in Sf21 cells. Recently, we demonstrated that $\mathrm{Sf} 21$ insect cells have catalase-less peroxisomes capable of fatty acid $\beta$-oxidation. ${ }^{22)}$ The number of peroxisomes is thought to be too low to accept the large amounts of heterologous proteins produced by the baculovirus-mediated expression systems. This result is consistent with the reports that heterologous large amounts of acylCoA oxidase and urate oxidase distribute in the cytoplasm and the nucleus and do not locate to a specific organelle in Sf9 cells. ${ }^{26,27)}$

It has been thought that the majority of peroxisomal $\mathrm{ABC}$ proteins function as a homodimer. ALDP and ALDRP have a strikingly different expression pattern in mouse tissues ${ }^{28)}$ and the pattern results in a different phenotype between the ALDP (ABCD1) and ALDRP (ABCD2) knockout mouse. ${ }^{29)}$ Additionally, Guimaraes et al ${ }^{30)}$ demonstrated the majority of mouse liver ALDP and PMP70 to be a homomeric protein because ALDP and ALDRP could not be co-purified with PMP70. Therefore, it is likely that the expression of either ALDP or ALDRP is sufficient for the formation of a functional homodimer in Sf21 cell membranes. In fact, we detected significant ATPase activities in Sf21 membranes in the case of individual expression of ALDP or ALDRP.

ATP binding and hydrolysis are tightly coupled to the transport of substrates by $\mathrm{ABC}$ proteins. Szentpetery et al. suggested that the ABC signature motifs in MRP1 were responsible for the accelerated hydrolytic activity upon interaction of the protein with its transporting substrates. ${ }^{31)}$ We have shown that in rat liver peroxisomes ATP tightly binds to both PMP70 and ALDP in the presence of $\mathrm{Mg}^{2+}$, the bound ATP 
is hydrolyzed to ADP in the presence of $\mathrm{Mg}^{2+}$, and the ADP produced becomes dissociated, which effects ATP hydrolysis turnover. ${ }^{13)}$ In PMP70, the binding and hydrolysis of ATP induced conformational changes in the boundary between the transmembrane and nucleotide-binding domain and in the helical domain between the Walker A and B motifs. ${ }^{32)}$ Using a protease-based approach, Guimaraes et al. have estimated that ALDP from human placenta is involved in the transport of long- and very long-chain acyl-CoA. ${ }^{33)}$ However, the correlation between the ATP binding and hydrolysis and the transport of substrate in peroxisomal $\mathrm{ABC}$ proteins has not yet been determined. Recently the function of several $A B C$ proteins expressing in insect cells has been determined by investigation of substrate-stimulated ATP hydrolytic activity. ${ }^{18,34,35)}$ In the present study, we expressed for the first time full-length ALDP and ALDRP in Sf21 membranes with ATPase and nucleotide-binding activities. The measurement of the ATPase activity of ALDP in Sf21 cell membranes might allow identification of its substrates. In addition, we have also shown that the heterologous ALDRP in Sf21 membranes was functional and the nucleotide-binding capacity significantly different from that of ALDP. This suggests the role of ALDRP in the ATP hydrolyzing reaction is different from that of ALDP.

Takahashi et al. have reported the detergent-soluble human ABCA1 from the Sf9 membrane exhibits significant ATPase activity before reconstitution in liposomes. ${ }^{36)}$ In the present study, however, the purified ALDPHis had little ATPase activity although the membrane containing ALDPHis showed significant ATPase activity even in the presence of detergent. The fact may indicate that the molecules fold properly only in the presence of certain lipids in the membranes. MRP purified from the MRP cDNA-transfected BHK-21 cells requires certain phospholipids for the expression of the ATPase activity. ${ }^{37)}$ Ste $6 \mathrm{p}$, a yeast $\mathrm{ABC}$ transporter, is also reported to require both exogenous lipid and the chemical chaperone glycerol to preserve the native activity. ${ }^{38)}$ In the present study, however, reconstitution of the purified ALDP in liposomes failed to exhibit the ATPase activity. Further work is required for determining the conditions for expressing the intrinsic ATPase activities.

In this study, we demonstrate for the first time that fulllength human ALDP and ALDRP can be expressed in Sf21 cells, having nucleotide-binding and ATP-hydrolyzing activities. In addition, the nucleotide-binding properties of ALDRP are different from those of ALDP. We suggest that the ATPase system using the Sf21 cell membrane could be an efficient tool for examining the interactions of peroxisomal ABC proteins with their substrates. Reconstitution of these proteins into lipid vesicles, and stimulation of the ATPase activity by various substrates are now under active investigation.

Acknowledgements Human $A L D$ cDNA was kindly gifted from Dr. Kamijo (Shinshu Univ., Japan). This study was supported by a Grant-in-Aid for "the Research Committee for Ataxic Diseases" of the Research on Measures for Intractable Diseases from the Ministry of Health, Welfare and Labour, Japan. Pacific Edit reviewed the manuscript prior to submission.

\section{REFERENCES}

1) Dean M., Hamon Y., Chimini G., J. Lipid Res., 42, 1007-1017 (2001).

2) van den Bosch H., Schutgens R. B., Wanders R. J., Tager J. M., Annu. Rev. Biochem., 61, 157-197 (1992).

3) Wanders R. J., Mol. Genet. Metab., 83, 16-27 (2004).

4) Takemoto Y., Suzuki Y., Tamakoshi A., Onodera O., Tsuji S., Hashimoto T., Shimozawa N., Orii T., Kondo N., J. Hum. Genet., 47, 590-593 (2002).

5) Suzuki Y., Takemoto Y., Shimozawa N., Imanaka T., Kato S., Furuya H., Kaga M., Kato K., Hashimoto N., Onodera O., Tsuji S., Brain Dev., 27, 353-357 (2005).

6) Dubois-Dalcq M., Feigenbaum V., Aubourg P., Trends Neurosci., 22, 4-12 (1999).

7) Moser H., Dubey P., Fatemi A., Curr. Opin. Neurol., 17, 263-269 (2004).

8) Hettema E. H., van Roermund C. W., Distel B., van den Berg M., Vilela C., Rodrigues-Pousada C., Wanders R. J., Tabak H. F., EMBO J., 15, 3813-3822 (1996).

9) Shani N., Sapag A., Valle D., J. Biol. Chem., 271, 8725-8730 (1996).

10) Lombard-Platet G., Savary S., Sarde C. O., Mandel J. L., Chimini G., Proc. Natl. Acad. Sci. U.S.A., 93, 1265-1269 (1996).

11) Kamijo K., Taketani S., Yokota S., Osumi T., Hashimoto T., J. Biol. Chem., 265, 4534 - 4540 (1990).

12) Holzinger A., Kammerer S., Roscher A. A., Biochem. Biophys. Res. Commun., 237, 152-157 (1997).

13) Tanaka A. R., Tanabe K., Morita M., Kurisu M., Kasiwayama Y., Matsuo M., Kioka N., Amachi T., Imanaka T., Ueda K., J. Biol. Chem., 277, 40142-40147 (2002).

14) Imanaka T., Aihara K., Suzuki Y., Yokota S., Osumi T., Cell Biochem. Biophys., 32, 131-138 (2000).

15) Imanaka T., Aihara K., Takano T., Yamashita A., Sato R., Suzuki Y., Yokota S., Osumi T., J. Biol. Chem., 274, 11968-11976 (1999).

16) Shimizu S., Imanaka T., Takano T., Ohkuma S., J. Biochem. (Tokyo), 112, 733-736 (1992).

17) Germann U. A., Methods Enzymol., 292, 427-441 (1998).

18) Ozvegy C., Litman T., Szakacs G., Nagy Z., Bates S., Varadi A., Sarkadi B., Biochem. Biophys. Res. Commun., 285, 111-117 (2001).

19) Uebel S., Plantinga T., Weber P. J., Beck-Sickinger A. G., Tampe R., FEBS Lett., 416, 359-363 (1997).

20) Imanaka T., Shiina Y., Takano T., Hashimoto T., Osumi T., J. Biol. Chem., 271, 3706-3713 (1996).

21) de Duve C., Pressman B. C., Gianetto R., Wattiaux R., Appelmans F., Biochem. J., 60, 604-617 (1955).

22) Kurisu M., Morita M., Kashiwayama Y., Yokota S., Hayashi H., Sakai Y., Ohkuma S., Nishimura M., Imanaka T., Biochem. Biophys. Res. Commun., 306, 169-176 (2003).

23) Chifflet S., Torriglia A., Chiesa R., Tolosa S., Anal. Biochem., 168, $1-4$ (1988).

24) Morita M., Takahashi I., Kanai M., Okafuji F., Iwashima M., Hayashi T., Watanabe S., Hamazaki T., Shimozawa N., Suzuki Y., Furuya H., Yamada T., Imanaka T., FEBS Lett., 579, 409-414 (2005).

25) Bradford M. M., Anal. Biochem., 72, 248-254 (1976).

26) Chu R., Usuda N., Reddy M. K., Liu C., Hashimoto T., Alvares K., Rao M. S., Reddy J. K., Biochem. Biophys. Res. Commun., 200, 178186 (1994).

27) Chu R., Varanasi U., Chu S., Lin Y., Usuda N., Rao M. S., Reddy J. K., J. Biol. Chem., 270, 4908-4915 (1995).

28) Troffer-Charlier N., Doerflinger N., Metzger E., Fouquet F., Mandel J. L., Aubourg P., Eur. J. Cell Biol., 75, 254-264 (1998).

29) Ferrer I., Kapfhammer J. P., Hindelang C., Kemp S., Troffer-Charlier N., Broccoli V., Callyzot N., Mooyer P., Selhorst J., Vreken P., Wanders R. J., Mandel J. L., Pujol A., Hum. Mol. Genet., 14, 3565-3577 (2005).

30) Guimaraes C. P., Domingues P., Aubourg P., Fouquet F., Pujol A., Jimenez-Sanchez G., Sa-Miranda C., Azevedo J. E., Biochim. Biophys. Acta, 1689, 235-243 (2004).

31) Szentpetery Z., Kern A., Liliom K., Sarkadi B., Varadi A., Bakos E., J. Biol. Chem., 279, 41670-41678 (2004).

32) Kashiwayama Y., Morita M., Kamijo K., Imanaka T., Biochem. Biophys. Res. Commun., 291, 1245-1251 (2002).

33) Guimaraes C. P., Sa-Miranda C., Azevedo J. E., J. Hum. Genet., 50, 
99-105 (2005).

34) Sarkadi B., Price E. M., Boucher R. C., Germann U. A., Scarborough G. A., J. Biol. Chem., 267, 4854-4858 (1992).

35) Cserepes J., Szentpetery Z., Seres L., Ozvegy-Laczka C., Langmann T., Schmitz G., Glavinas H., Klein I., Homolya L., Varadi A., Sarkadi B., Elkind N. B., Biochem. Biophys. Res. Commun., 320, 860-867 (2004)
36) Takahashi K., Kimura Y., Kioka N., Matsuo M., Ueda K., J. Biol. Chem., 281, 10760-10768 (2006).

37) Chang X. B., Hou Y. X., Riordan J. R., J. Biol. Chem., 272, 30962 30968 (1997).

38) Ketchum C. J., Schmidt W. K., Rajendrakumar G. V., Michaelis S., Maloney P. C., J. Biol. Chem., 276, 29007-29011 (2001). 